Journal Of Al Azhar University Engineering Sector

Vol. 12, No. 43, January, 2017, 612-619

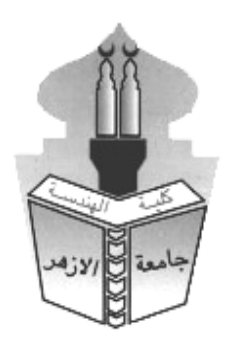

\title{
PRINCIPLES AND PRACTICE OF DECONSTRUCTION IN ARCHITECTURAL EDUCATION WHEN AND HOW DECONSTRUCTION SHOULD BE INTRODUCED TO ARCHITECTURE STUDENTS
}

\author{
Mohammed F. M. Mohammed ${ }^{1}$ and Rahma M. Doheim ${ }^{2}$ \\ ${ }^{1}$ Architecture Department, Cairo University, Egypt \\ ${ }^{2}$ Architecture Department, Assiut University, Egypt
}

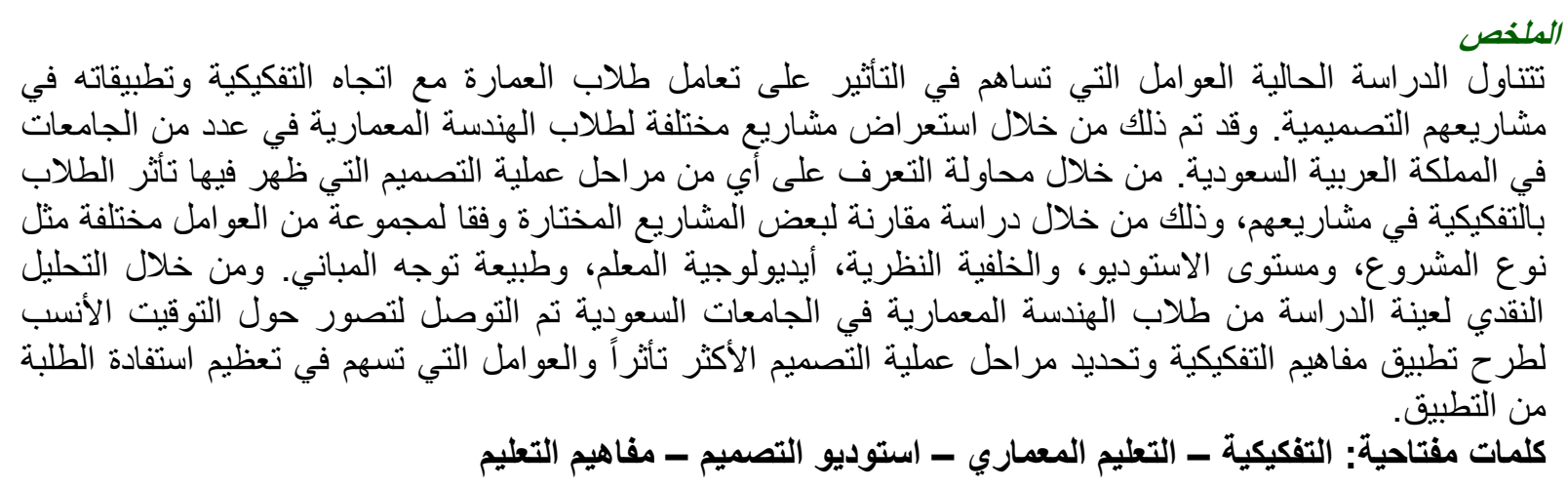

\section{ABSTRACT}

This paper discusses the factors that contribute to influence Architecture students with the deconstruction trend in their projects. This was achieved through reviewing different projects for Architecture students from several universities in the KSA. By determining the stage of the design process in which students get influenced by de-constructivism in their projects some selected projects were put in comparison with respect to different factors such as project type, studio level, theoretical background, instructor's ideology, and verticality/ horizontality of buildings. Through a critical insight and data analysis it was possible to conclude the relationship between the stage of the design process in which Architecture students in Saudi Universities get influenced by and the factors that contribute to be influenced by de-constructivism.

\section{KEYWORDS: DECONSTRUCTION; ARCHITECTURAL EDUCATION; DESIGN STUDIO; PEDAGOGY}

\section{INTRODUCTION}

Deconstruction is an architectural trend that challenges the ideas of unity, regularity, order and stability, and rejects the relationship between the type of activity and the form of a building. Deconstruction distorts walls and roof and adopts sculpturing the building. Deconstruction trend has created a prolonged public debate, and it was harshly criticized due to the confusion and discomfort that it creates. This revolutionary approach has been adopted by many students in architecture schools, and it is considered to be a source of inspiration to architects. However, there is another point of view consider that deconstruction left architects with no clear vision of what to do, consequently, no skill or knowledge that architecture 
PRINCIPLES AND PRACTICE OF DECONSTRUCTION IN ARCHITECTURAL EDUCATION

WHEN AND HOW DECONSTRUCTION SHOULD BE INTRODUCED TO ARCHITECTURE STUDENTS

students need to learn through their education; but rather learn to behave, dress and talk in a culturally acceptable way for architects (Mitrovi, 2011).

In the literature of architectural pedagogy, the interpretation of deconstruction and its impact on the educational outcomes have been discussed heavily. To be able to determine the key factors that contribute to the different levels of how students interpret deconstruction in their work, it is important to discuss the factors that affect teaching design studios where Architectural education is mainly provided. It is also important to discuss to what extent those key factors affect students' creativity where students are encouraged to be creative, innovative and interactive in their design ideas.

There are many teaching and assessing methods followed in design studios that would affect significantly the final product. Many factors affect students' performance in their design studios. Some architecture students adopt deconstruction trend in their designs, others don't. Hence, this paper provides answers to when and how should deconstruction be introduced to Architecture students.

\section{LITERATURE REVIEW}

Many studies have discussed the architectural education and how it can be improved to raise the quality and creativity of students' work especially in design studios. Although the differences in the architectural curriculum among architecture schools all over the world, architecture courses can be categorized under only two categories, design studio and theoretical courses. However, design studio is the core of all architecture courses and the most dominant in architectural education. In other words, the architectural education is studio oriented, in which all other courses are auxiliary and complementary. The experience that students go through in the design studio course is different than all other theoretical courses. It is the time when students use their imagination and creativity to solve design problems and make decisions (Gharaati, 2006).

In order to understand how to design, it is important to know first what design is. Design has different interpretation in the literature. However, there are five main characteristics that can describe design. The first characteristic, is the design activities including imaging (conceiving images beyond the given information), presenting (communicating and expressing the images) and testing presentation with the information. Secondly, is the "types of information" to build up knowledge for the design activities. The third is "shifting visions of final product", in which designers modify their image of the final product throughout the design process. The fourth is the "domain of acceptable responses" in which designers choose from alternatives the most convenient. And the fifth characteristic is "producing the end product", which is a result of the evolvement of the design activities (Billings and Akkach,1992; Salama, 1995)

With a thoroughly review in several studies, many key factors that contribute to influencing students design decisions was derived. Those key factors are discussed briefly in the following.

\section{IDEOLOGIES AND METHODS OF TEACHING ARCHITECTURE}

How to design? Many factors contribute to how students perceive design and how they perform in their architecture design studios. Architecture Design studio is the core course of Architectural education system, in which students learn how to design (Gharaati, M. 2006). The architectural education is studio oriented. However, challenges facing the Architectural education are mainly coming from the different ideologies and methods of teaching architecture, and the architectural curriculum and courses taught which differs from a program to another.

The ideologies and methods of teaching architecture are a crucial concern that affects how students perceive architecture. The individual teachers who carry those different ideologies and teaching methods are the ones who teach how to design. According to Billings and Akkach (1992), ideologies and teaching methods in contemporary architectural design are as varied as the teachers. In contemporary architectural design, some teaching ideologies are based on rationalize and systematize the design process, others are based on broadening the perspective of design through the involvement of wide range of disciplines, and others are based on a linear systematic manner (Billings and Akkach,1992). Salama (1995) has interpreted three approaches for designing, the intuitive model or "Black box approach", the rational model or "Glass box approach", and the participatory 
model or "Human Dialogue approach". However Salama, A. (1995) discussed the revolutionary studio teaching approaches that have been developed in response to the conventional approaches.

The importance of individual experimentation and experience-based education has been emphasized in the Architectural Education. Philosophers and education theorist have come to the conclusion that students should be actively involved in their pedagogy. Providing an "open and liberating environment", which is called flexible education system maximizes students' opportunity to practice and get the experience they need for their career, and reveals their latent potential. In such an educational system teachers' role is to observe students, and students in this system participate actively and influence directly their pedagogy (Gharaati, Mehran; 2006).

\section{COMPLEMENTARY COURSES IN THE ARCHITECTURAL EDUCATION}

The theoretical and technical courses offered in any architectural program are designed to provide a complementary knowledge and skills acquired to the design studio projects to allow students to tackle their design projects with a comprehensive manner and holistic approach. However, instructors struggle to integrate all the information acquired in the design studios either because the lack of coordination or mismatching between the information offered and design studio sequence, or because of students follow different study plans (Mahgoub, 2007).

Talking about the courses that increase students' creativity and ability to create innovative ideas, teaching history of architecture was emphasized in many studies. History or architecture courses increases students' design capabilities and enhance their level of creativity by introducing different Architectural schools and trends (Durmus \& Gur, 2011; Ulusoy \& Kuyrukcu, 2012; Yildirim et.al, 2012; Uzunoglu \& Quriesh, 2012; Kurt, 2009). According to Ulusoy and Kuyrukcu (2012), Architecture students will not be able to produce innovative ideas without knowing the history of Architecture which enables students to make connection between past and future.

Other studies discussed the importance of using AutoCAD and other programs as a tool to increase the ability of architecture students to generate more innovative ideas and help them to make more creative forms (Kurt, 2011; Yavuz \& Akcay, 2012). According to Kurt (2011), it is necessary for architecture students to simulate the real world context throughout the design process using computer aided programs and virtual and digital studios.

Others discussed the crucial role of holding critique sessions as a tool to evaluate and educate students and how it helps students to be aware of all aspects of the project and it helps them to build an Architectural sense (Utaberta et.al, 2011). Utaberta et.al (2011) discussed the implemented methods of critique in teaching studios, and emphasized the importance of allowing students to express and discuss his/her own perceptions and ideas with instructors and peers and expose him/her self to their judgments through critique sessions.

The design studio has been a site of play for teaching the approaches of architecture trends. Derrida finds it is a threat for deconstruction design studio if it became the norm (Coyne, 2011). Comparing studio work for students from different levels allowed seeing that many students resisting order and coherence even in the early levels and before having enough background. However, a thoroughly look in studio work for students in different architecture schools, different levels is discussed in the following.

\section{The analytical Study}

The analytical part of the study aims introduce a classification of a set of indicators associated with levels of students' intake and dealing with the deconstruction trend in their designs in attempt to provide the most appropriate methods, techniques and timing to train them to deal with this trend. To achieve this aim, A sample of students' design project was selected to apply a series of analytical studies according to a certain methodology will be reviewed in the next section:

Study sample

The study sample was selected through the works of some of the students in a number of Saudi universities (included two governmental universities: King Saud University and Umm Al-Qura University and a private on: Effat University). A range of students' design projects was selected by selecting the projects which displays any of the features or the effects of the deconstruction trend at any level, with requesting some data and information about these projects, the academic level in which they were introduced, as well as some information about the program offered to the students.

The researchers reported a large number of projects that have been studied and classified according to the methodology which will be reviewed in the next section. 

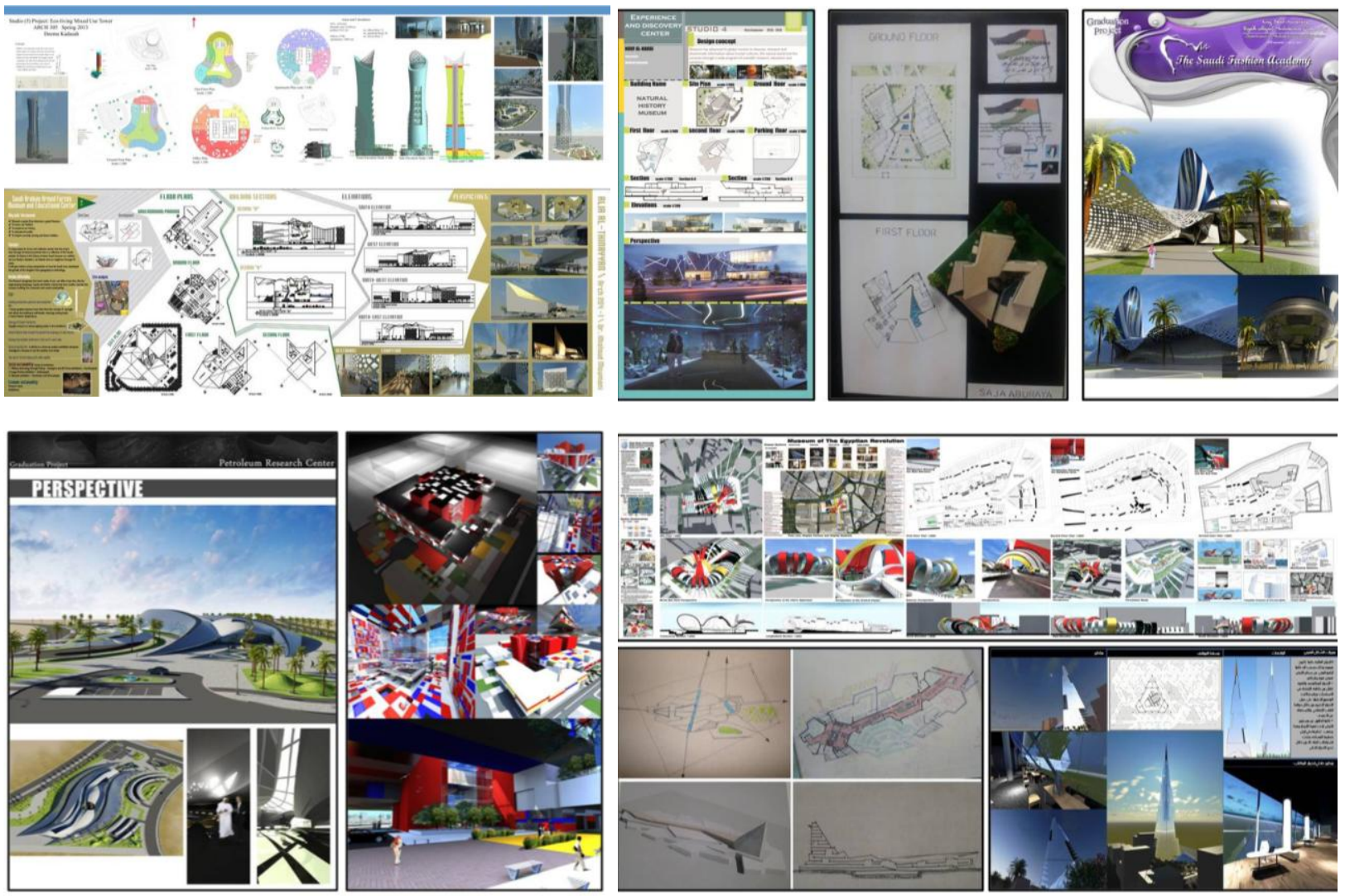

Figure 1. Sample of the studied projects (Effat University, 2013).

\section{Analysis Methodology}

the study of the projects was applied according to three main phases; In the first phase, studying the reflection of the deconstruction trend on the project and to what extent is the depth of impact level of this trend on the project, This reflection has been classified into four graduated levels, The first level covers the projects that confined influenced by the trend only in the form dimension at the level of facades and the outer envelope of the building. The second level annexations the projects that explain the impact at the level of masses and mass formation. The third level covers the projects that spread the impact to the level of functional and spatial relationships. The fourth level includes the projects that appeared to show a greater level of depth approach used as a holistic approach where deconstruction is reflected in all impact levels including the ideas and implications behind the design.

In the second phase; a range of factors related to and affecting the students' design decisions were studied through several evaluation criteria. In the first criterion, the level of the student has been determined and divided into three basic levels (including the primary level (freshman), intermediate (junior), and advanced (senior)); as in the second criterion, it was determined whether the student has been subjected to a theoretical study on the deconstruction trend in its various aspects; as in the third criterion, is determining the project prototype and the classification based on the division between buildings with simple or multiple activities in addition to the nature of the activity. While in the fourth criterion, it was studied the instructor attitude in terms of his encouragement to the students to provide creative ideas, solutions and treatments, and it should be noted here that the classification is not intended to describe the personal profile of the instructor (traditional - balanced - innovative ), but is intended to characterization of the process of guidance for students during the stages of the design process and the aspects that are focused on during this process (and this classification has been put in through a set of queries that have been directed to these supervisors)

Then comes the third phase attempting to link the output of the previous two phases to get a group of indicators that shows how the factors in the second phase influence the levels of impact in the first phase.

Results and analysis of output indicators:

(Review of the outputs of the three phases and then comment on the third) 
PRINCIPLES AND PRACTICE OF DECONSTRUCTION IN ARCHITECTURAL EDUCATION WHEN AND HOW DECONSTRUCTION SHOULD BE INTRODUCED TO ARCHITECTURE STUDENTS

Table 1 and Table 2, shows the output of monitoring for each of the first and second phases of the various studied projects, and shows the different levels of treatment in the first phase as well as the range of factors affecting the second phase.

Table1. Output of the first phase of the various studied projects (Source: Authors)
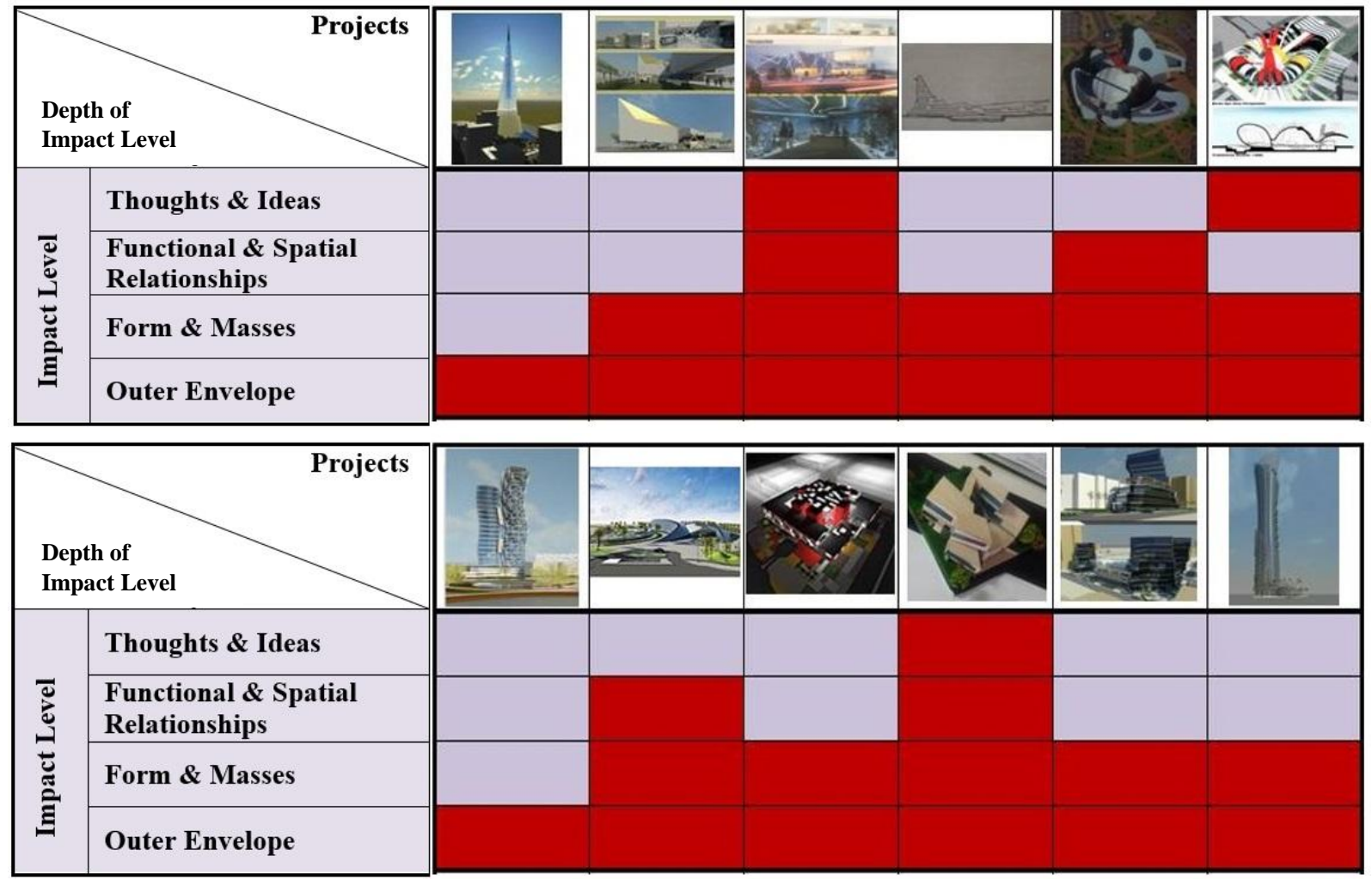
PRINCIPLES AND PRACTICE OF DECONSTRUCTION IN ARCHITECTURAL EDUCATION WHEN AND HOW DECONSTRUCTION SHOULD BE INTRODUCED TO ARCHITECTURE STUDENTS

Table 2. Output of the second phase of the various studied projects (Source: Authors)

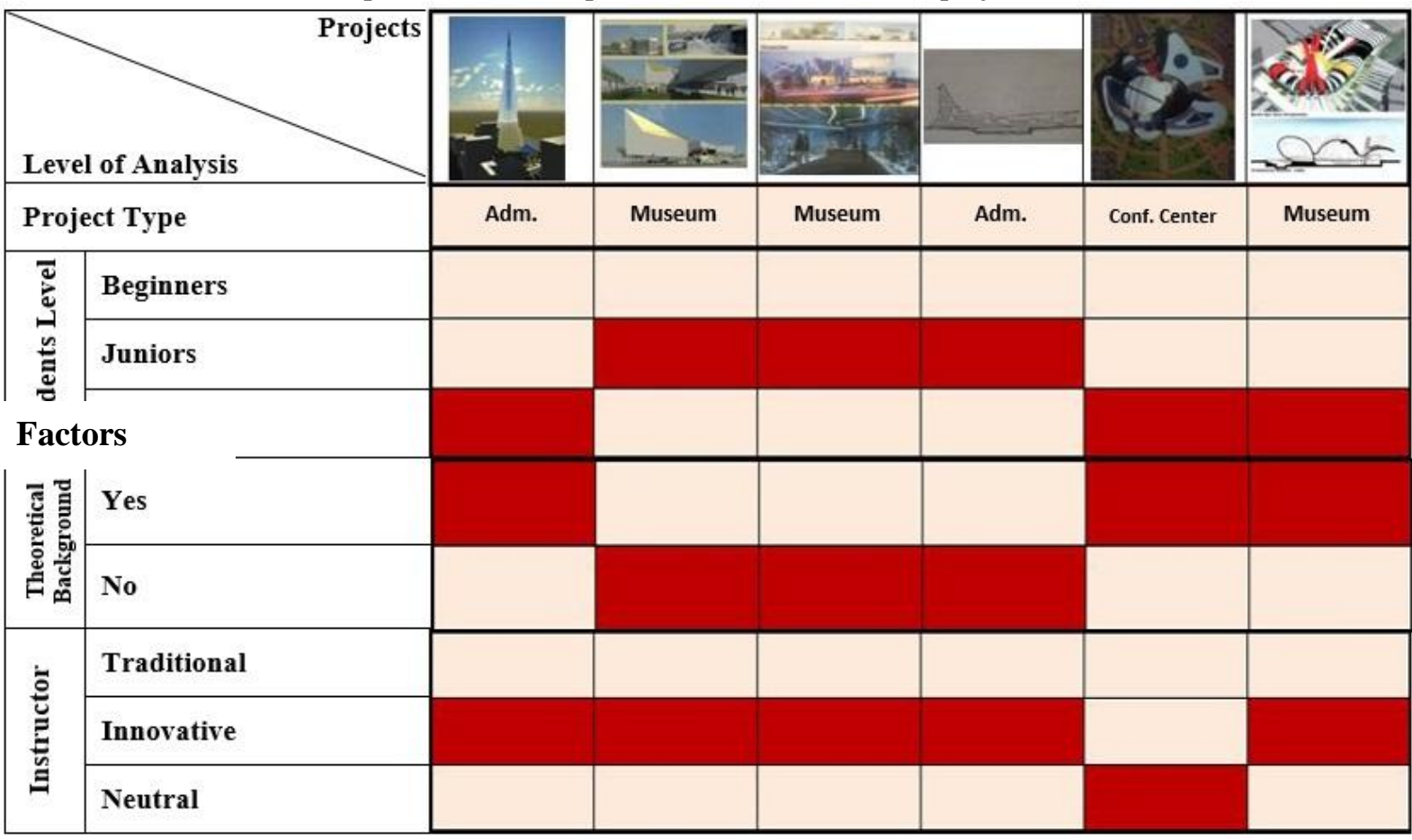

\begin{tabular}{|l|l|l|l|l|l|l|l|}
\hline \multicolumn{1}{|l|}{ Factors } & Projects & & & & & & \\
\hline
\end{tabular}

By rearranging the outputs of the study to place the projects with similar levels of vulnerability in separate groups and study factors associated in each group, as shown in Table 3, we can draw a set of indicators and directories as follows: 
PRINCIPLES AND PRACTICE OF DECONSTRUCTION IN ARCHITECTURAL EDUCATION

WHEN AND HOW DECONSTRUCTION SHOULD BE INTRODUCED TO ARCHITECTURE STUDENTS

Table 3. Classification of the various studied projects according to levels of vulnerability (Source: Authors)

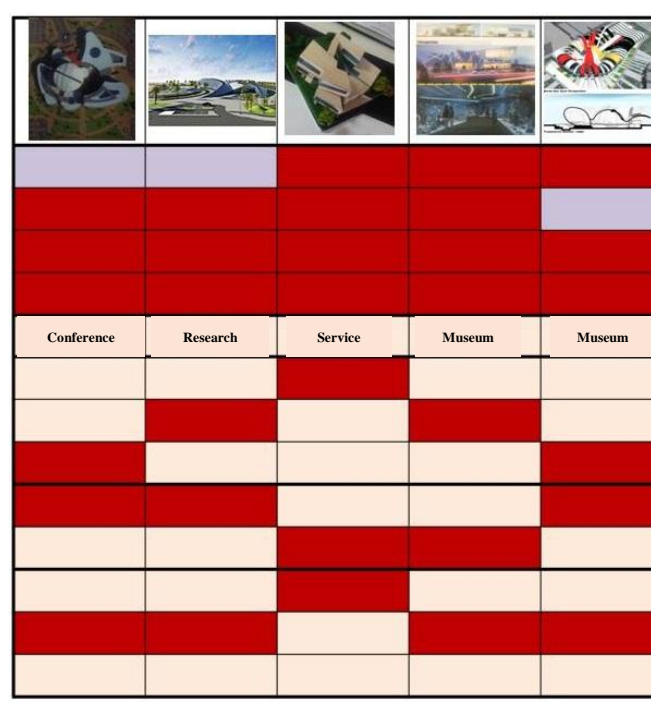

High
vulnerability to the most profound starting with the third and fourth level (the level of spatial and functional relationships as well as the ideas and implications) that most of these projects have been presented to the students in the advanced or medium levels, but they may have been exposed to the deconstruction trend through some theoretical courses, and they have been encouraged clearly through their instructors to deal with untraditional ideas and solutions, as it seems one of the most important influencing factors here that all of these projects are with functional nature for public buildings in which they are dealing with a variety of public functions.

-

The review of the group of projects that shows lower levels of vulnerability which include the second level (Form and Masses), shows that most of these projects have been provided to students in the intermediate levels, and some of them have been subjected to the deconstruction trend through some theoretical courses while others weren't exposed to this trend, as most of them have been encouraged clearly through their instructors to deal with untraditional ideas and solutions, and for the nature of the projects, despite the fact that most of these projects are public buildings, but the nature of functions with repetitive pattern in these projects may be a factors that contributed to limit the development of the impact for higher levels.

-

As it appears to the review of the group of projects that shows vulnerable only at the level of the outer envelope, that these projects have been provided to students in levels ranging from intermediate and advanced, and they have been exposed mostly to the deconstruction trend through some theoretical courses, while the effect of their instructors ranged between encouraging them clearly to deal with traditional and untraditional ideas and solutions, It seems that the most influential factor in this group is the nature of the projects for this group which contained residential or administrative projects having the quality of a repetitive pattern of functions in addition to the emergence of the vertical direction of these projects, which seems a significant factor that may represent a challenge and perhaps a barrier to the emergence of deeper dealing levels.

\section{Results and Recommendations}

The analysis of the different cases resulted in the following interesting findings:

The students' abilities of handling and dealing with the deconstruction trend of higher and deeper insight develop better when they are in higher study level.

Introducing different intellectual trends through theoretical courses represents an essential pillar to help the students to be able to deal with these trends in the design process. 
The nature of the projects in terms of function and development direction apparently an important factor in determining the possibility and level approach to the deconstruction trend in the design process, Where the projects with diverse functions seem more appropriate to deal with this trend, as the projects with vertical dimension seem more difficult and may represent an obstacle to apply this approach.

The process of encouraging students (through their instructors) to deal and expose to untraditional solutions and ideas plays a vital and important role in supporting the students design process.

Based on the results above it is recommended to provide students with a minimum of theoretical background in Architecture at early study level and before introducing the intellectual trends through their design projects. Along with that, it is recommended to encourage students to analyse and discuss those intellectual trends to assure they understand the core of the philosophy of the different theories and trends.

\section{REFERENCES}

1. Billings, K., \& Akkach, S. (1992). A study of ideologies and methods in contemporary architectural design teaching: Part 1: Ideology. Design studies, 13(4), 431-450.

2. Coyne, R. (2011). Derrida for architects. Routledge

3. Daneshgarmoghhaddam, G. (2012). An investigation on influencing parameters of comprehending the design problem as an initiation stage for the novice designers in architectural education. ProcediaSocial and Behavioral Sciences, 31, 568-574.

4. Durmus, S., \& Gur, S. O. (2011). Methodology of deconstruction in Architectural education. ProcediaSocial and Behavioral Sciences, 15, 1586-1594.

5. Gadwick, M. (2004). Back to school: architectural education, the information and the argument. Chichester: Wiley.

6. Gharaati, M. (2006). A new view on Architectural Design Studio; Comprehensive studio. In AlQawasmi, J. \& Vasquez de Velasco, G.P. (Eds.) Changing Trends in Architectural Design Education (pp. 107-114). CSAAR.

7. Kurt, S. (2009). An analytic study on the traditional studio environments and the use of constructivist studio in the architectural design education. Procedia-Social and Behavioral Sciences, 1(1), 401-408.

8. Kurt, S. (2011). Use of constructivist approach in Architectural education. Procedia-Social and Behavioral Sciences, 15, 3980-3988.

9. Mitrache, A. (2013). Spatial Sensibility in Architectural Education. Procedia-Social and Behavioral Sciences, 93, 544-548.

10. Mitrovi, B. (2011). Philosophy for architects. Princeton Architectural Press.

11. Salama, A. (1995). New Trends in Architectural Education-Designing the Design Studio. New Jersey: Tailored Text and Unlimited Potential Publishing .

12. Salama, A. M., \& Wilkinson, N. (2007). Design Studio Pedagogy: Horizons for the Future. International Journal of Architectural Engineering, 1(3), 194-206.

13. Uzunoglu, S.S. (2012). Aesthics and architectural education. Procedia-Social and Behavioral Sciences, $51,90-98$.

14. Ulusoy, M, \& Kuyrukcu, E. Y. (2012). The meaning and importance of the traditional architecture in Architecture education; Gonen Winter School. Procedia-Social and Behavioral Sciences, 47, 21202126.

15. Utaberta, N., Hassanpour, B., CheAni, A. I., \& Surat, M. (2011). Reconstructing the Idea of Critique Session in Architecture Studio. Procedia-Social and Behavioral Sciences, 18, 94-102

16. Uzunoglu, S. S., Quriesh, A. (2012). A method of adopting construction education in Architectural design education. Procedia-Social and Behavioral Sciences, 51, 546-552.

17. Yavuz, A., \& Akcay, F. (2012). Development of an approach for producing architectural form in architectural design education. Procedia-Social and Behavioral Sciences, 51, 222-227.

18. Yildirim, M. T., Yavuz, A.,O., \& Kirci, N. (2012). Experience of traditional teaching methods in architectural design education: Mimesis Technique. Procedia-Social and Behavioral Sciences, 51, 234238. 